\title{
Assessment Method of Business Process Model of EKD
}

\author{
Sílvia Inês Dallavalle de Pádua ${ }^{1}$ and Ricardo Yassushi Inamasu ${ }^{2}$ \\ ${ }^{1}$ University of São Paulo- College of Economics, Business and Accounting at Ribeirão \\ Preto - FEARP-USP-Brazil \\ ${ }^{2}$ Embrapa - Brazilian Agricultural Research Corporation
}

Brazil

\section{Introduction}

The business processes are the fundamental building blocks for a successful organization. The information technology (IT), when directed to the management and improvement of business processes, has helped the organization to complete its enterprise vision and improve its competitive position. The needs of the business should be provided by information technology looking forward to achieve business goals as competition, competitiveness and strategies. Systems that do not meet the needs of the organization may impede the development of the business.

The organizational modeling, in this context, facilitates the comprehension of business environment and it is recognized as a valuable activity for the development information system in accordance to Nurcan and Barrios (2003) and Persson (2000). The process of organizational modeling should bring answers to these questions: why, what, who, which, when, where and how. For so many, there are several modeling techniques in the literature with a significant range of notations.

The approach that will be used in this work is the EKD - Enterprise Knowledge Development a methodology that provides a systematic and controlled way to analyze, understand, develop and document an organization and its components, using the Organizational Modeling (Rolland et at, (2000), Bubenko et al. (1998) and Nurcan (1998)). The EKD also contributes to make a decision in modern organizations that are highly dependent on information technology (Nurcan and Barrios (2003) and Nurcan and Rolland (2003)). According to Bubenko et al. (1998), the types of submodels of EKD method are: Goals Model, Business rules model, Concepts Model, Business Process Model, Actors and Resources Model and Requirements and Technicians Components Model. This methodology is explained in detail by: Pádua et al (2004a), Dallavalle and Cazarini (2001), and Pádua (2001). The main problem of the approach of Organizational Modeling, including the EKD, is the lack of a more complex technical analysis. It has been discussed by several authors the problem of informal structure of organizational techniques and business processes models.

Among them, some can be mentioned: Dongen et al (2007); Lenz et al. (2005); Mevius and Oberw (2005); Padua et al. (2004b); Koubarakis and Plexousakis (2002); Junginger et al.

The paper was published in: Gest. Prod. vol.15 no.3 São Carlos Sept./Dec. 2008 in portuguese language 
(2001); Jonkers et al. (2003); Dehnert (2003), Padua (2004); Padua et al. (2003), Padua et al. (2002) and Aalst (1999).

According to Padua (2004), the syntax and the semantics of the EKD business processes model are not well defined formally and rigorously. As a result, the EKD business processes model may be ambiguous and of difficult analysis mainly in more complex systems, not being possible to check the consistency and completeness of the model. The absence of formal semantics also makes difficult the use of more efficient techniques analysis. In this work, these problems were studied under an approach based on Petri nets. The formalism of Petri nets makes it a powerful technique of modeling for representation of processes, allowing display of: competition, parallelism, synchronization, non-determinism and mutual exclusion. The main concepts of Petri nets are discussed by Padua et.al. (2002)

Many works have valued the formal structure of Petri nets for business processes representation, among them some can be mentioned: Verbeek et al. (2007), Guan et. al. (2006), Zhang and Shuzen (2006), Ou-Yang and Lin (2007), Aalst and Hee (2002), Padua (2004), Padua et al (2003), Padua et al (2004), Padua et al. (2002) and Aalst (1999). Therefore, this work presents a method of assessment of the Business Processes Model of the EKD. In order to the method could be created, it was necessary to develop the formalization of the business processes model of the EKD and the mapping of the business processes model on Petri nets.

The method of evaluation was applied in the process model of the human resources strategic plan developed in the project ESPRIT ELEKTRA ("Electrical Enterprise Transforming Knowledge for Applications") (BUBENKO et al 1998). The model mapped on Petri nets was simulated on the tool "Petri Net Tools" developed and implemented at the Simulation and Discrete Control Systems Laboratory at University of São Paulo in São Carlos (Soares, 2001). The editor had six modules. Four modules were in operation: Petri network L/T (local/transition), MFG (Mark Flow Graph), SFC (Sequential Flow Chart) and stochastic PN.

The editor allows the following types of analysis: reachability tree; incidence matrix; limitation; vivacity; verification of the final state, transitions and invariant places.

In the studies of Aalst and Hee (2002), Verbeek et al. (2002), Salimifard and Wright (2001) Aalst (1999), Aalst and Hofstede (2000), Voorhoeve (2000) and Mold and Valk (2000) the business processes are directly modeled on Petri nets.

In this study, the construction of the business processes model followed the EKD organizational modeling method and not directly onto Petri nets. The procedure of mapping the business processes model onto Petri nets was developed based on Petri nets place/transition. The power of analysis of the properties of the model would be reduced in case the mapping was based on extended and high-level nets. Methods to assess Petri colored net are computationally expensive and feasible only for simple models (Jensen, 1997).

The work is structured in nine sections, including this introduction. On section two important concepts related to nets of Petri in the context of business processes model will be introduced. In section three, a presentation of the formal model of business processes is made. Sections four and five will present the model of business processes on Petri nets map and assessment method of the EKD business processes model. The section six shows the application method. The ending considerations are outlined on section seven.

\section{Petri Net and business process model}

According to Hofstede and Aalst (2000), some mistakes are easily identified on the models of Petri nets like deadlock, when it is not possible performing any task; livelock, when a case 
is in infinite loop, being possible performing tasks, but no progress is possible and deadtask, when a task can never be run on any situation.

Some studies investigate the use of subclasses of Petri nets to increase the decision-making power without reducing the power of modeling of Petri networks. In these subclasses some structural restrictions are made on Petri nets. The subclass of Petri nets denominated freechoice enables the modeling of the parallelism conflict and the synchronization. When a place is an input of several transitions, this place is the only input of these transitions. Thus, all transitions will be qualified or no one will be, making possible the choice of the event freely. Formally, the definition of free-choice is: Be a Petri net $=(\mathrm{P}, \mathrm{T}, \mathrm{I}, \mathrm{O}, \mathrm{K})$. I is the set of inputs to the transitions and $\mathrm{O}$ is the set of the outputs of the transitions. $\mathrm{K}$ is the capacity of places. This network is classified as a network of free-choice if, and only if, $I\left(t_{j}\right)=$ $\left\{p_{i}\right\}$ ou $\mathrm{O}\left(\mathrm{p}_{\mathrm{i}}\right)=\left\{\mathrm{t}_{\mathrm{j}}\right\}, \forall \mathrm{t}_{\mathrm{j}} \in \mathrm{T}$ and $\mathrm{p}_{\mathrm{i}} \in \mathrm{I}\left(\mathrm{t}_{\mathrm{j}}\right)$.

The main problem of the approach of Organizational modeling, including the EKD, is the lack of objective technical analysis. In this case, Petri nets have an excellent potential to solve this problem, since they have graphics representation, they are easy to learn, they work as a language of communication among experts from several areas, allowing the description of static and dynamic aspects of the system to be represented, and still have the Mathematical formalism that allows the use of methods of analysis. The several applications of Petri nets on Engineering are presented in Padua et al. (2003). Since Zisman (1977) used Petri nets to model workflow for the first time, many authors have published studies that also looked for the integration of the two subjects. Among them, some can be mentioned: Chrzastowski-Wachtel et al. (2003), Rinderle et al. (2003), Dehnert (2003), Grigorova (2003) and Verbeck et al. (2002), Aalst and Hee (2002) and Padua et al. (2004), explain that there are several reasons to use Petri nets for business processes modeling: formal semantics, graphic nature, expressiveness, properties, analysis and the advantage of not being dependent on the supplier.

The criterion of verifying correctness defined to workflow-nets is called soundness. Sound is synonymous of correct according to Aalst and Hee (2002). Aalst (1997) developed a technique that verifies that the procedure meets the following requirements (of soundness): no task should exist that does not contribute to the processing of cases; for any case, the procedure eventually will end and at the moment that the procedure ends for specific cases, all references to this case should be removed.

\subsection{Formalizing the business processes model}

To perform the mapping of the Business Processes Model onto Petri Nets, based on Aalst (1999), a formal definition of the Model of Business Processes of the EKD (BPM-EKD) was created.

In this way, it was possible to describe the requirements that a Business Processes Model should meet in order to do the mapping be development. Seeking for formal definition of the Model of Business Processes, it was created a set of connectors to the Business Processes Model of EKD. The set of connectors is represented by $C$ and it is composed by $C_{A N D}, C_{O R}$, $\mathrm{C}_{\mathrm{J}}, \mathrm{C}_{\mathrm{S}}, \mathrm{C}_{\mathrm{IP}}$ and $\mathrm{C}_{\mathrm{PI}}$. The connectors $\mathrm{C}_{\mathrm{OR}}$ and $\mathrm{C}_{\mathrm{AND}}$ were created to identify exclusive choice and parallelism in order that the cases of parallelism and choice won't be modeled exactly in the same way, creating ambiguities and difficulties of comprehension. The connectors $C_{J}$ and $C_{S}$ define the connectors type join and split. To describe the nature of the flow of processes and their interactions, there is a set of terms, used in Workflow Management Coalition (1996) and in Aalst and Hee (2002), which are presented as follows: 
- AND-Split: point where, from a single line of flow, two or more lines start and are performed in parallel.

- AND-Join: point where two or more activities, running in parallel, converge on a single line of common flow.

- OR-Split: point where a single line of flow makes a decision among a number of options.

- OR-Join: point at which an activity that has a number of alternatives, directs itself to a single option

According to these settings AND-Split, AND-Join, OR-Split and OR-Join the construction of Figure 1 are not allowed on formal BPM-EKD.

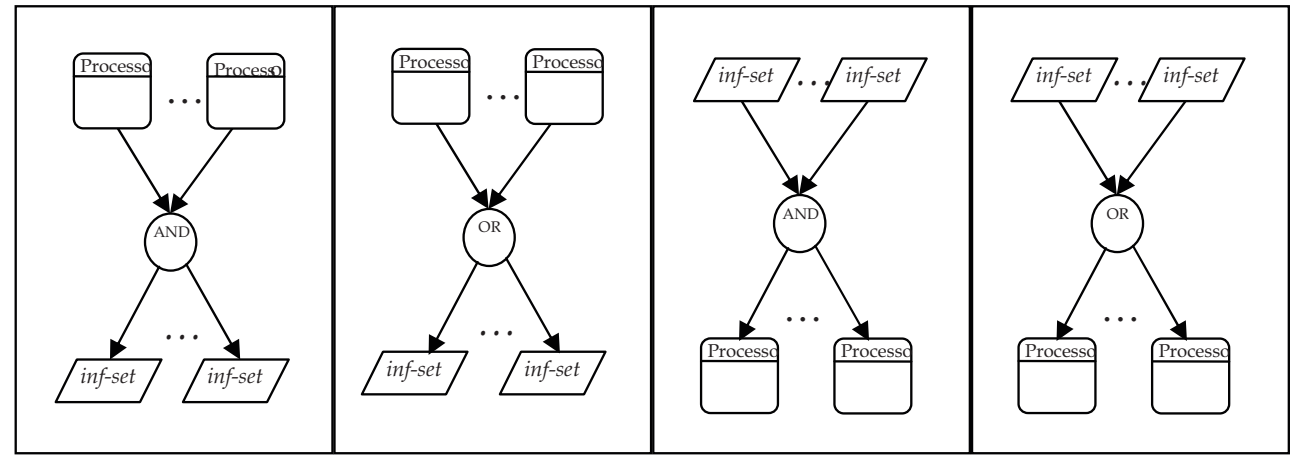

Fig. 1. Constructions that are not allowed in a formal BPM-EKD

The connectors $C_{I P}$ and $C_{P I}$ show that a connector $C$ is a path from one inf-set to one process or a path from a process to an inf-set.

The initial and final states are not specified on Business Processes Model of EKD, it was necessary to create such states in order that the formalization could be effectively accomplished. This situation will be explained during the course of this chapter.

Definition 1. A BPM-EKD is a quintuple (I, P, C, Q, A):

- $\quad I$ is a finite set of inf-set (set of information).

- $\quad P$ is a finite set of processes,

- $\quad \mathrm{C}$ is a finite set of logical connectors,

- $\quad \mathrm{Q} \in \mathrm{C} \rightarrow\{\mathrm{AND}, \mathrm{OR}\}$ é is a function that maps each connector within an specific type of connector.

- $\quad \mathrm{A} \subseteq(\mathrm{I} \times \mathrm{P}) \cup(\mathrm{P} \times \mathrm{I}) \cup(\mathrm{I} \times \mathrm{C}) \cup(\mathrm{C} \times \mathrm{I}) \cup(\mathrm{P} \times \mathrm{C}) \cup(\mathrm{C} \times \mathrm{P})$ is a set of arcs.

A BPM-EKD is composed of three types of elements: inf-set -set of information (I), processes $(\mathrm{P})$ and connectors $(\mathrm{C})$. The type of each connector is given by the function $\mathrm{Q}: \mathrm{Q}(\mathrm{c})$ is the type (AND or OR) of a connector $\mathrm{c} \in \mathrm{C}$. The connection A specifies a set of arcs connecting processes, set of information (inf-set) and connectors. The definition 1 shows that it is not allowed to have an arc connecting two processes or two inf-sets or two connectors.

Definition 2. A directed path $\mathrm{p}$ from a node $\mathrm{n}_{1}$ to a node $\mathrm{n}_{\mathrm{k}}$, is a sequence $\left\langle\mathrm{n}_{1}, \mathrm{n}_{2}, \ldots \mathrm{n}_{\mathrm{K}}\right\rangle$ sequence, such as $\left\langle n_{i}, n_{i+1}\right\rangle \in A$ for $1 \leq i \leq k-1$. $p$ is elementary if, and only if, for any of the nodes ni and nj in $\mathrm{p}, \mathrm{i} \neq \mathrm{j} \rightarrow \mathrm{n}_{\mathrm{i}} \neq \mathrm{n}_{\mathrm{j}}$. 
The definition of directed path will be used to limit the number of construction of routes that can be used. This definition allows the definition of $C_{I P}$ (set of connectors from one infset to one process) and $C_{P I}$ (set of connectors from one process to one inf-set). $C_{I P}$ and $C_{P I}$ divide the set of connectors $C$. Based on the $Q$ function, the $C$ is portioned in $C_{A N D}$ and $C_{O R}$. The set $C_{J}$ and $C_{S}$ is used to classify (rank) the connectors in connectors join or split.

Definition 3. Considering BPM-EKD $=(I, P, C, Q, A)$ a:

- $\quad \mathrm{N}=\mathrm{I} \cup \mathrm{P} \cup \mathrm{C}$ is a set of nodes of BPM-EKD

- $\mathrm{C}_{\mathrm{AND}}=\{\mathrm{c} \in \mathrm{C} \mid \mathrm{Q}(\mathrm{c})=\mathrm{AND}\}$;

- $\mathrm{C}_{\mathrm{OR}}=\{\mathrm{c} \in \mathrm{C} \mid \mathrm{Q}(\mathrm{c})=\mathrm{OR}\}$;

- Para $n \in N$ : $\bullet=\{m \mid(m, n) \in A\}$ is the set of input nodes, and $n \bullet=\{m \mid(n, m) \in A\}$ is the set of output nodes

- $\quad \mathrm{C}_{\mathrm{J}}=\{\mathrm{C} \in \mathrm{C}|\quad| \bullet \mathrm{C} \mid \geq 2\}$ is the set of join connectors

- $\quad C s=\{c \in C|| c \bullet \mid \geq 2\}$ is the set of join connectors

- $\quad \mathrm{C}_{\mathrm{IP}} \subseteq \mathrm{C}$ such that $\mathrm{c} \in \mathrm{C}_{\mathrm{IP}}$, if and only if there is a path $\mathrm{p}=\left\langle\mathrm{n}_{1}, \mathrm{n}_{2}, \mathrm{n}_{3}\right\rangle$, tal que $\mathrm{n}_{1} \in \mathrm{I}$, $\mathrm{n}_{2} \in \mathrm{C}, \mathrm{n}_{3} \in \mathrm{P}$; and

- $\quad C_{P I} \subseteq C$ such that $c \in C_{P I}$ if and only if there is a path $p \mathrm{p}=\left\langle\mathrm{n}_{1}, \mathrm{n}_{2}, \mathrm{n}_{3}>\right.$, tal que $\mathrm{n}_{1} \in \mathrm{P}$, $\mathrm{n}_{2} \in \mathrm{C}, \mathrm{n}_{3} \in \mathrm{I}$.

Definition 3 enables to specify the additional requirements an BPM-EKD chain should satisfy.

Definition 4. A Business Process Model of EKD meets the following requirements:

- $\quad$ The sets I, $\mathrm{P}$ and $\mathrm{C}$ are pairwise disjoint, i.e, $\mathrm{I} \cap \mathrm{P}=\varnothing, \mathrm{I} \cap \mathrm{C}=\varnothing$, and $\mathrm{P} \cap \mathrm{C}=\varnothing$;

- $\quad$ For each $\mathrm{i} \in \mathrm{I}:|\bullet \mathrm{i}| \leq 1$ and $|\mathrm{i} \bullet| \leq 1$;

- There is at least one inf set $\mathrm{i} \in \mathrm{I}$, such that $|\bullet \mathrm{i}|=0$ (inf-set start);

- There is at least one inf-set $i \in I$, such that $|i \bullet|=0$ (inf-set end);

- $\quad$ For each $\mathrm{p} \in \mathrm{P}:|\bullet \mathrm{p}|=1$ and $|\mathrm{p} \bullet|=1$;

- For each $c \in \mathrm{C}:|\bullet \mathrm{c}| \geq 1$ and $|\mathrm{c} \bullet| \geq 1$;

- The graph induced by BPM-EKD C is weakly connected, if for every two nodes $\mathrm{n} 1, \mathrm{n} 2 \in$ $\mathrm{N},(\mathrm{n} 1, \mathrm{n} 2) \in\left(\mathrm{A} \cup \mathrm{A}^{-1}\right)^{*}$;

- $\quad C_{\mathrm{J}}$ and $\mathrm{Cs}$ partition de $\mathrm{C}$, i.e., $\mathrm{C}_{\mathrm{J}} \cap \mathrm{Cs}=\varnothing$ and $\mathrm{C}_{\mathrm{J}} \cup \mathrm{Cs}=\mathrm{C}$; e

- $\quad \mathrm{C}_{\mathrm{IP}}$ and $\mathrm{C}_{\mathrm{PI}}$ partition de C, i.e., $\mathrm{C}_{\mathrm{IP}} \cap \mathrm{C}_{\mathrm{PI}}=\varnothing$ and $\mathrm{C}_{\mathrm{IP}} \cup \mathrm{C}_{\mathrm{PI}}=\mathrm{C}$.

In the line of Aalst (1999), the first requirement states that each component has a unique identifier (name). The connector names are omitted in the diagram of an BPM-EKD. The other requirements correspond to restrictions on the relation A. Inf Sets cannot have multiple input arcs and there is at least one start inf set and one final inf set. Each function has exactly one input arc and one output arc. For every two nodes $\mathrm{n} 1$ and $\mathrm{n} 2$ there is a path from $\mathrm{n} 1$ to $\mathrm{n} 2$ (ignoring the direction of the arcs). A connector $\mathrm{c}$ is either a join connector $((|c \bullet|=1$ and $|\bullet c| \geq 2)$ jc or a split connector $(|\bullet c|=1$ and $|c \bullet| \geq 2)$. The last requirement states that a connector $\mathrm{c}$ is either on a path from an inf set to a process or on a path from a process to an inf set. The BPM-EKD is syntactically correct, if all the requirements stated in Definition 4 are satisfied.

\subsection{The business processes model on Petri Nets mapping}

In this section, the Business Processes Model on Petri nets mapping procedure will be presented. The mapping procedure was developed based on Petri nets place / transition. The definitions (1) and (4) presented only report the syntax of the Business Processes Model of EKD and not the semantics. 
The places represent inf-sets or are necessary constructions to model the behavior of connector of BPM-EKD. The transitions represent processes or are representing the behavior of the connector. Each connector $\mathrm{c} \in \mathrm{C}$ corresponds to places, transitions and / or arcs.

The connector can correspond to a number of arcs of Petri net or to a small network of places and transitions. The connector OR corresponds to a behavior of a place. The AND connector corresponds to a transition behavior. On definition 5 the element Place of Petri nets will be represented by $\mathrm{L}$ to avoid confusion with the P of BPM-EKD process. The definition 5, presented as follows, shows how the mapping of the connectors of BPM-EKD is developed in this study.

On the BPM-EKD context the arcs always have equal weight as 1 because places correspond to conditions. On a Petri net, which corresponds to one correct (sound) BPM-EKD, a place will never contain multiple brands. The net is secure. The states with multiple brands in one place are results of projects errors and to identify these errors it is necessary to consider nonsecure nets.

Definition 5. Let $\mathrm{BPM}-\mathrm{EKD}=(\mathrm{I}, \mathrm{P}, \mathrm{C}, \mathrm{Q}, \mathrm{A}) \cdot N(\mathrm{EKD})=\left(\mathrm{L}^{\mathrm{PN}}, \mathrm{T}^{\mathrm{PN}}, \mathrm{F}^{\mathrm{PN}}\right)$ is the Petri net generated by EPC BPM-EKD:

$$
\mathrm{L}^{\mathrm{PN}}=\mathrm{I} \cup\left(\bigcup_{\mathrm{c} \in \mathrm{C}} \mathrm{L}_{\mathrm{c}}^{\mathrm{PN}}\right)
$$

The set of places $\left(\mathrm{L}^{\mathrm{PN}}\right)$ is formed by the union of all inf-sets with places that were included to represent connectors $\left(\bigcup_{\mathrm{c} \in \mathrm{C}} \mathrm{L}_{\mathrm{c}}^{\mathrm{PN}}\right)$.

$$
\mathrm{T}^{\mathrm{PN}}=\mathrm{P} \cup\left(\bigcup_{\mathrm{c} \in \mathrm{C}} \mathrm{T}_{\mathrm{c}}^{\mathrm{PN}}\right)
$$

The set of transitions $\left(\mathrm{T}^{\mathrm{PN}}\right)$ is formed by the union of all Processes with transitions that were included to represent connectors $\left(\bigcup_{c \in C} T_{c}^{P N}\right)$.

$$
\mathrm{F}^{\mathrm{PN}}=(\mathrm{A} \cap((\mathrm{I} \times \mathrm{P}) \cup(\mathrm{P} \times \mathrm{I}))) \cup\left(\bigcup_{\mathrm{c} \in \mathrm{C}} \mathrm{F}_{\mathrm{c}}^{\mathrm{PN}}\right)
$$

The set of arcs of the net (FPN) is formed by arcs of model that range from I to $\mathrm{P}$ and from $\mathrm{P}$ to $I$ and the union of arcs included to represent connectors $\left(\bigcup_{c \in C} F_{c}{ }^{P N}\right)$.

Following, the definitions of $\mathrm{L}_{\mathrm{c}}{ }^{\mathrm{PN}}, \mathrm{T}_{\mathrm{c}}{ }^{\mathrm{PN}}$ and $\mathrm{F}_{\mathrm{c}}{ }^{\mathrm{PN}}$ will be presented according to the mapping rules related to the type of connectors of BPM-EKD. Right after each definition, examples that represent the utilized (applied) rules for mapping the connectors of EKD-MPN on Petri nets are presented.

\section{Rule 1}

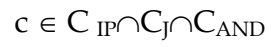

When the connector $c$ belongs to $C_{I P}$ (path from inf-set to process) intersection of $C_{J}$ (join) intersection of Cand, the definitions of $\mathrm{L}_{c}{ }^{\mathrm{PN}}, \mathrm{T}_{\mathrm{c}}{ }^{\mathrm{PN}}$ and $\mathrm{F}_{\mathrm{c}}{ }^{\mathrm{PN}}$ are the following:

1. $\mathrm{L}_{\mathrm{c}}{ }^{\mathrm{PN}}=\varnothing$

2. $\mathrm{T}_{\mathrm{C}} \mathrm{PN}=\varnothing$ 
3. $\mathrm{F}_{\mathrm{c}} \mathrm{PN}=\{(x, y) \mid \mathrm{x} \in \bullet \mathrm{c}$ e $\mathrm{y} \in \mathrm{c} \bullet\}$

The equation I states that it is not necessary to add places to represent this connector. The equation II states that it is necessary to add transitions to represent this connector. The equation III states that the arcs that go from the set of the connector input to the set of the connector output.

In this case, it is noticed that the connector AND-join corresponds to two or more arcs on Petri nets if, and only if, the output is a process. On Figure 2 an example of mapping of the connector $\mathrm{c} \in \mathrm{C}_{\mathrm{IP}} \cap \mathrm{C}_{\mathrm{J}} \cap \mathrm{C}_{\mathrm{AND}}$ is presented.

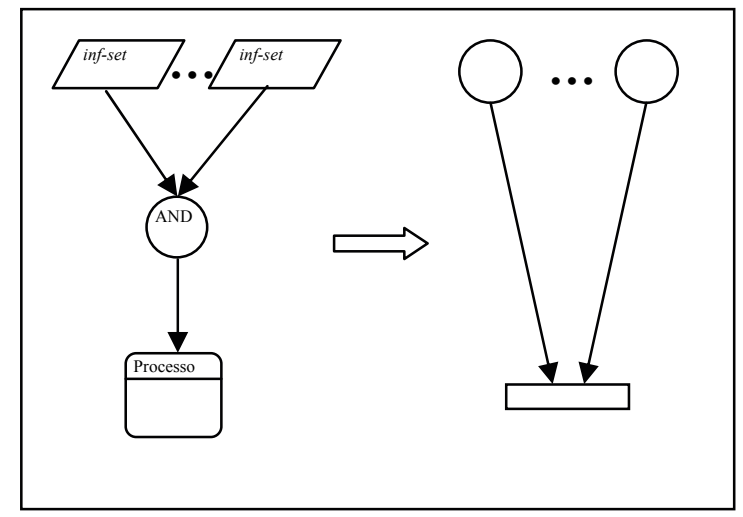

Fig. 2. Example of $\mathbf{C}_{\text {AND }}$ Mapping among two or more inf-sets for one process.

\section{Rule 2}

$$
\mathrm{c} \in \mathrm{C}_{\mathrm{PI}} \cap \mathrm{C}_{\mathrm{J}} \cap \mathrm{C}_{\mathrm{AND}}
$$

When the connector $c$ belongs to $C_{P I}$ (path from process to inf-set) intersection of $C_{J}$ (join) intersection of $\mathrm{C}_{\mathrm{AND}}$, the definitions of $\mathrm{L}_{\mathrm{c}}{ }^{\mathrm{PN}}, \mathrm{T}_{\mathrm{c}}{ }^{\mathrm{PN}}$ e $\mathrm{F}_{\mathrm{c}}{ }^{\mathrm{PN}}$ are the following:

1. $\mathrm{L}_{\mathrm{c}}^{\mathrm{PN}}=\left\{l_{x^{c}} \mid \mathrm{x} \in \bullet \mathrm{c}\right\}$

2. $\mathrm{T}_{\mathrm{C}}^{\mathrm{PN}}=\{t c\}$

3. $\mathrm{F}_{\mathrm{c}}^{\mathrm{PN}}=\left\{\left(x, l_{x^{c}}\right) \mid \mathrm{x} \in \bullet c\right\} \cup\left\{\left(l_{x^{c}}, t^{c}\right) \mid \mathrm{x} \in \bullet c\right\} \cup\left\{\left(t^{c}, x\right) \mid \mathrm{x} \in \mathrm{c} \bullet\right\}$

On equation $I$ it is stated that to represent this connector it is necessary to add one place for each process of the connector input. On equation II it is indicated that to represent this connector it is necessary to add a transition. On equation III it is stated that to represent the connector it is necessary to add arcs that connect the transitions to the places of the connector inputs, among the places and the corresponding transitions to the connector and between the transition and the place of the connector output.

In this case, the connector AND-join behaves as a transition. It is added one place for each process of the connector input. On figure 3 one example of the connector mapping $c \in C$ $\mathrm{P}_{\mathrm{I}} \cap \mathrm{C}_{\mathrm{J}} \cap \mathrm{C}_{\mathrm{AND}}$ is presented.

\section{Rule 3}

$$
\mathrm{c} \in \mathrm{C}_{\mathrm{IP}} \cap \mathrm{C}_{\mathrm{J}} \cap \mathrm{C}_{\mathrm{OR}}
$$




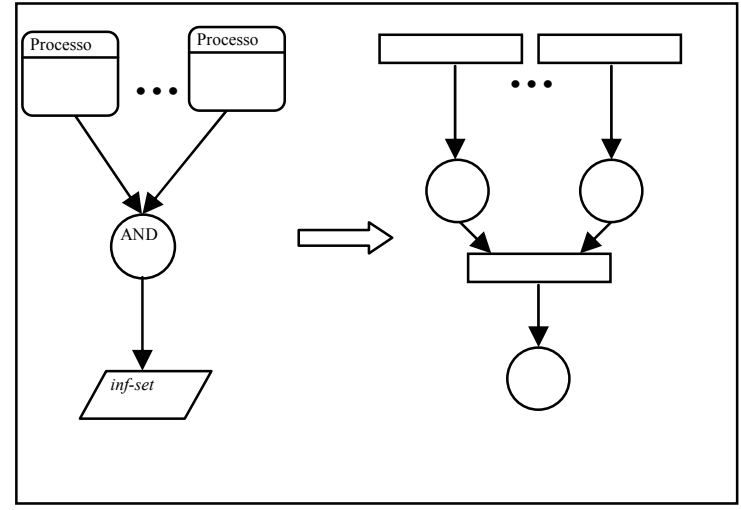

Fig. 3. Example of $\mathrm{C}_{\mathrm{AND}}$ Mapping among two or more processes for one inf-set.

When the connector $\mathrm{c}$ belongs to $\mathrm{C}_{\mathrm{IP}}$ (path from inf-set to process) intersection of $\mathrm{C}_{\mathrm{J}}$ (join) intersection of $\mathrm{C}_{\mathrm{OR}}$, the definitions of $\mathrm{L}_{\mathrm{C}}{ }^{\mathrm{PN}}, \mathrm{T}_{\mathrm{c}}{ }^{\mathrm{PN}}$ and $\mathrm{F}_{\mathrm{c}}{ }^{\mathrm{PN}}$ are the following:

1. $\mathrm{L}_{\mathrm{c}} \mathrm{PN}=\{l c\}$

2. $\mathrm{T}_{\mathrm{c}}^{\mathrm{PN}}=\left\{t_{x}{ }^{\mathrm{c}} \mid \mathrm{x} \in \bullet \mathrm{c}\right\}$

3. $\mathrm{F}_{\mathrm{c}}^{\mathrm{PN}}=\left\{\left(x, t_{x} c\right) \mid \mathrm{x} \in \bullet \mathrm{c}\right\} \cup\left\{\left(t_{x}{ }^{c}, l c\right) \mid \mathrm{x} \in \bullet \mathrm{c}\right\} \cup\{(l c, x) \mid \mathrm{x} \in \mathrm{c} \bullet\}$

On equation I it is stated that to represent the connector it is necessary to add one place. On equation II it is established that to represent this connector it is necessary to add one transition for each inf-set of the connector input. On equation III it is stated that to represent this connector it is necessary to add a set of arcs from the places to the transitions of the connector input, among the transitions and the place that corresponds to the connector and between the place and the transition of the connector output.

The connector OR-join has the behavior of a place when the connector is $C_{I P}$. On Figure 4 an example of mapping of the connector $\mathrm{c} \in \mathrm{C}_{\mathrm{IP} \cap} \cap \mathrm{C}_{\mathrm{J}} \cap \mathrm{C}_{\mathrm{OR}}$. is presented.

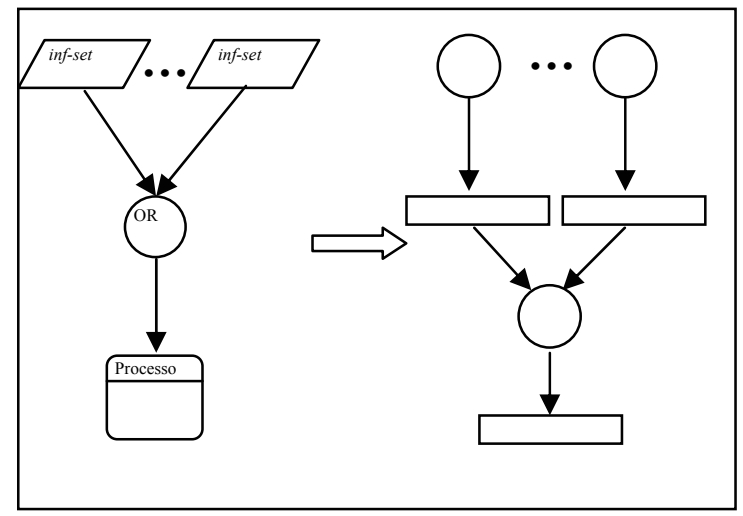

Fig. 4. Example $\mathrm{C}_{\mathrm{OR}}$ Mapping among two or more inf-sets for one process.

Rule 4

$$
\mathrm{c} \in \mathrm{C}_{\mathrm{PI}} \cap \mathrm{C}_{\mathrm{J}} \cap \mathrm{C}_{\mathrm{OR}}
$$


When the connector $\mathrm{c}$ belongs to $\mathrm{C}_{\mathrm{PI}}$ (path from process to inf-set) intersection of $\mathrm{C}_{\mathrm{J}}$ (join) intersection of $\mathrm{C}_{\mathrm{OR}}$, the definitions of $\mathrm{L}_{\mathrm{c}}{ }^{\mathrm{PN}}, \mathrm{T}_{\mathrm{c}} \mathrm{PN}^{\mathrm{N}}$ and $\mathrm{F}_{\mathrm{c}}{ }^{\mathrm{PN}}$ and $\mathrm{F}_{\mathrm{C}} \mathrm{PN}$ are the following:

1. $\mathrm{L}_{\mathrm{C}} \mathrm{PN}=\varnothing$

2. $\mathrm{T}_{\mathrm{C}}^{\mathrm{PN}}=\varnothing$

3. $\mathrm{F}_{\mathrm{c}} \mathrm{PN}=\{(x, y) \mid \mathrm{x} \in \bullet$ c e $\mathrm{y} \in \mathrm{c} \bullet\}$

On equation $\mathrm{I}$ it is presented that it is not necessary to add places to represent this connector. On equation II it is stated that it is not necessary to add transitions to represent this connector. On equation III it is presented that the arcs set is between the input set and the output set.

The connector OR-join corresponds to two or more arcs on Petri nets if, and only if, the connector is $\mathrm{C}_{\mathrm{PI}}$. On Figure 5 an example of mapping of the connector $\mathrm{c} \in \mathrm{C}_{\mathrm{PI}} \cap \mathrm{C}_{\mathrm{J}} \cap \mathrm{C}_{\mathrm{OR}}$ is presented

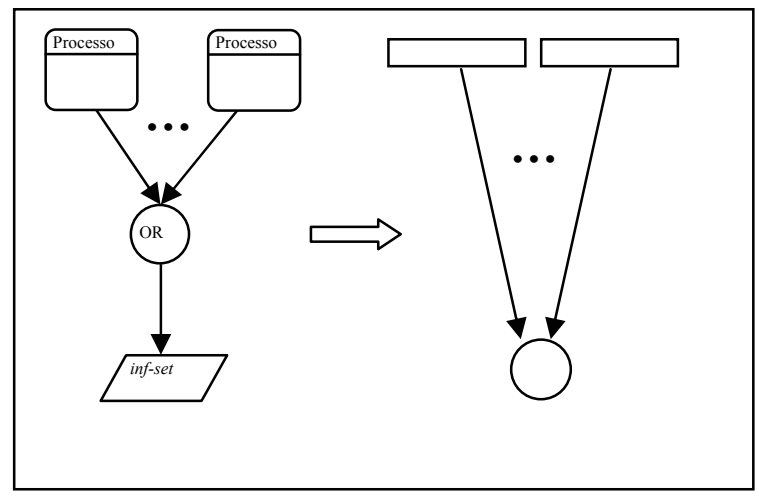

Fig. 5. Example of $\mathrm{C}_{\mathrm{OR}}$ Mapping among two or more process for an inf-set.

\section{Rule 5}

$$
\mathrm{c} \in \mathrm{C}_{\mathrm{IP}} \cap \mathrm{C}_{\mathrm{S}} \cap \mathrm{C}_{\mathrm{AND}}
$$

When the connector $c$ belongs to $C_{I P}$ (path from inf-set to process) intersection of $C_{S}$ (join) intersection of $\mathrm{C}_{\mathrm{AND}}$, the definitions of $\mathrm{L}_{\mathrm{c}}{ }^{\mathrm{PN}}, \mathrm{T}_{\mathrm{c}}{ }^{\mathrm{PN}}$ and $\mathrm{F}_{\mathrm{c}}{ }^{\mathrm{PN}}$ are the following:

1. $\mathrm{L}_{\mathrm{c}}^{\mathrm{PN}}=\left\{l_{x^{c}} \mid \mathrm{x} \in \mathrm{c} \bullet\right\}$

2. $\mathrm{T}_{\mathrm{c}} \mathrm{PN}=\{t c\}$

3. $\mathrm{F}_{\mathrm{c}}^{\mathrm{PN}}=\left\{\left(x, t^{c}\right) \mid \mathrm{x} \in \bullet \mathrm{c}\right\} \cup\left\{\left(t^{c}, l_{x^{c}}\right) \mid \mathrm{x} \in \mathrm{c} \bullet\right\} \cup\left\{\left(l_{x^{c}}, x\right) \mid \mathrm{x} \in \mathrm{c} \bullet\right\}$

On equation I it is presented that it is necessary to add one place for each connector output. On equation II it is stated that to represent this connector it is necessary to add one transition. On equation III it is presented that the arcs set needed to represent this connector must be between the place and one corresponding transition to the connector, among one transition and the places of the connector output and among the places of the connector output and the transition.

Thus, the connector AND-split of type $C_{I P}$ behaves as a transition followed by a number of places equal to a number of processes. On figure 6 one example of mapping of the connector $c \in \mathrm{C}_{\mathrm{IP}} \cap \mathrm{C}_{\mathrm{S}} \cap \mathrm{C}_{\mathrm{AND}}$ is presented. 


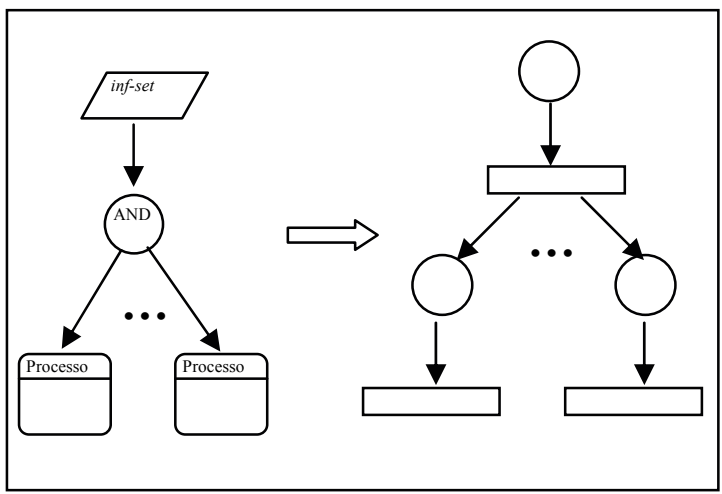

Fig. 6. Example of $\mathrm{C}_{\mathrm{AND}}$ mapping a inf-set for to or more process.

\section{Rule 6}

$$
\mathrm{c} \in \mathrm{C}_{\mathrm{PI}} \cap \mathrm{C}_{\mathrm{S}} \cap \mathrm{C}_{\mathrm{AND}}
$$

When the connector $\mathrm{c}$ belongs to $\mathrm{C}_{\mathrm{IP}}$ (path from process to inf-set ) intersection of $\mathrm{C}_{\mathrm{S}}$ (join) intersection of $\mathrm{C}_{\mathrm{AND}}$, the definitions of $\mathrm{L}_{\mathrm{C}}{ }^{\mathrm{PN}}, \mathrm{T}_{\mathrm{c}}{ }^{\mathrm{PN}}$ e $\mathrm{F}_{\mathrm{c}}{ }^{\mathrm{PN}}$ are the following:

1. $\mathrm{L}_{\mathrm{c}}^{\mathrm{PN}}=\varnothing$

2. $\mathrm{T}_{\mathrm{c}}^{\mathrm{PN}}=\varnothing$

3. $\mathrm{F}_{\mathrm{c}} \mathrm{PN}=\{(x, y) \mid \mathrm{x} \in \bullet \mathrm{c}$ e $\mathrm{y} \in \mathrm{c} \bullet\}$

On equation I it is presented that it is not necessary to add places to represent this connector. On equation II it is stated that it is not necessary to add transitions to represent this connector. On equation III it is presented that the arcs set is between the input set and the output set.

The connector AND-split corresponds to a number of arcs on Petri nets if, and only if, the output is two or more inf-sets. On Figure 7 an example of the connector mapping $c \in C$ $\mathrm{PI}_{\mathrm{PI}} \cap \mathrm{C}_{\mathrm{S}} \cap \mathrm{C}_{\mathrm{AND}}$ is presented.

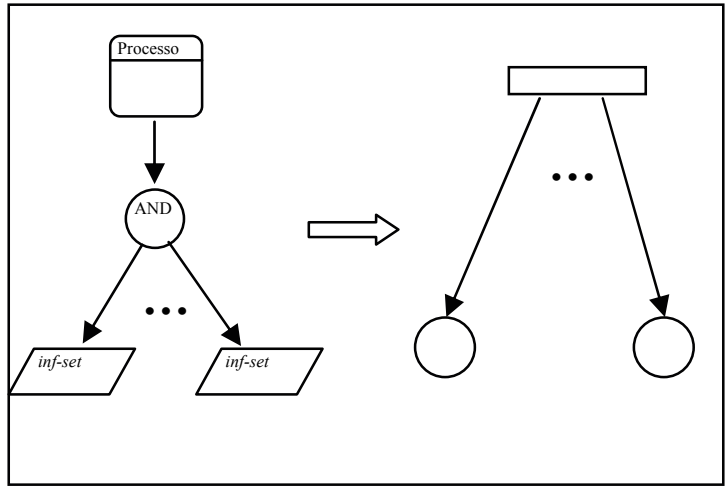

Fig. 7. Example of $\mathrm{C}_{\mathrm{AND}}$ Mapping based one process to two or more inf-sets. 


\section{Rule 7}

$$
\mathrm{c} \in \mathrm{C}_{\mathrm{IP}} \cap \mathrm{C}_{\mathrm{S}} \cap \mathrm{C}_{\mathrm{OR}}
$$

When the connector $\mathrm{c}$ belongs to CIP (path from inf-set to process) intersection of $\mathrm{C}_{\mathrm{S}}$ (join) intersection of $\mathrm{C}_{\mathrm{OR}}$, the definitions of $\mathrm{L}_{\mathrm{C}}{ }^{\mathrm{PN}}, \mathrm{T}_{\mathrm{c}}{ }^{\mathrm{PN}}$ and $\mathrm{F}_{\mathrm{c}}{ }^{\mathrm{PN}}$ are the following:

1. $\mathrm{L}_{\mathrm{C}}{ }^{\mathrm{PN}}=\varnothing$

2. $\mathrm{T}_{\mathrm{C}} \mathrm{PN}=\varnothing$

3. $\mathrm{F}_{\mathrm{c}} \mathrm{PN}=\{(x, y) \mid \mathrm{x} \in \bullet \mathrm{c}$ e $\mathrm{y} \in \mathrm{c} \bullet\}$

On equation I it is presented that it is not necessary to add places to represent this connector. On equation II it is stated that it is not necessary to add transitions to represent this connector. On equation III it is presented that the arcs set is between the input set and the output set.

The connector OR-split corresponds to a number of arcs on Petri nets if, and only if, the output is two or more processes On Figure 9 an example of the connector mapping $c \in C$ $\mathrm{IP} \cap \mathrm{C}_{\mathrm{s}} \cap \mathrm{C}_{\mathrm{OR}}$. is presented.

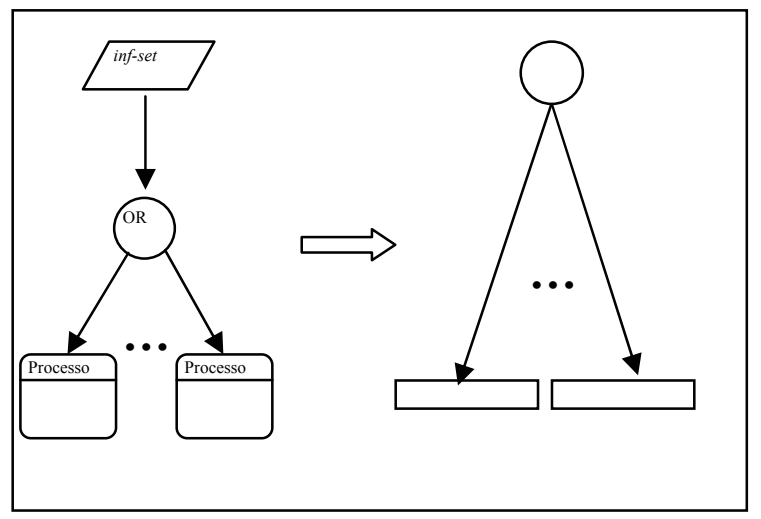

Fig. 8. Example of $\mathrm{C}_{\mathrm{OR}}$ Mapping from one inf-set to two or more processes

\section{Rule 8}

$$
\mathrm{c} \in \mathrm{C}_{\mathrm{PI}} \cap \mathrm{C}_{\mathrm{S}} \cap \mathrm{C}_{\mathrm{OR}}
$$

When the connector $\mathrm{c}$ belongs to $\mathrm{C}_{\mathrm{PI}}$ (path from process to inf-set) intersection of $C_{S}$ (join) intersection of $C_{O R}$, the definitions of $L_{c}{ }^{P N}, T_{c}{ }^{P N}$ e $F_{c}{ }^{P N}$ are the following:

1. $\mathrm{L}_{\mathrm{c}}^{\mathrm{PN}}=\{l c\}$

2. $\mathrm{T}_{\mathrm{C}} \mathrm{PN}=\left\{t_{x^{c}} \mid \mathrm{x} \in \mathrm{c} \bullet\right\}$

3. $\mathrm{F}_{\mathrm{c}} \mathrm{PN}^{\mathrm{N}}=\{(x, l c) \mid \mathrm{x} \in \bullet \mathrm{c}\} \cup\left\{\left(l^{c}, t_{x} c\right) \mid \mathrm{x} \in \mathrm{c} \bullet\right\} \cup\left\{\left(t_{x} c, x\right) \mid \mathrm{x} \in \mathrm{c} \bullet\right\}$

On equation I it is stated that to represent this connector it is necessary to add one place. On equation II it is presented that it is necessary to add a transition for each inf-set of the connector output. On equation III it is stated that the set of arcs should be between the initial transition and the correspondent place to the connector, among the place and the transitions 
of the connector output and among the transitions of the connector output and the places. The only way to exist a place with more than one output arc is the mapping of the connector OR-split from a process to two or more inf-sets. The rules of mapping ensure that the number of transitions is equal to the number of places. The net is free choice. On figure 9 one example of mapping of the connector $\mathrm{c} \in \mathrm{C}_{\mathrm{PI}} \cap \mathrm{C}_{\mathrm{S}} \cap \mathrm{C}_{\mathrm{OR}}$ is presented.

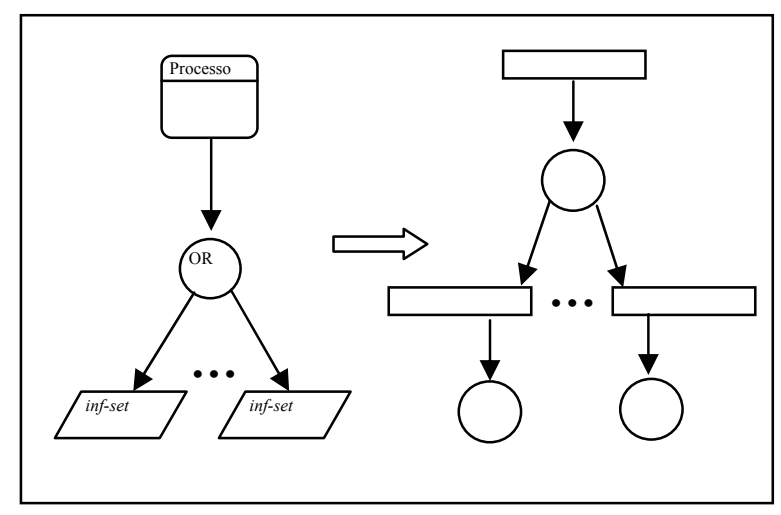

Fig. 9. Example of $\mathrm{C}_{\mathrm{OR}}$ Mapping from one process to two or more inf-sets

The BPM-EKD (I, P, C, Q, A) is a Business process model of EKD and $\mathrm{PN}=\mathrm{N}(\mathrm{BPM}-\mathrm{EKD})$ the Petri net generated by BPM-EKD. PN is free choice.

Definition 6. A BPM-EKD is a regular only if:

- BPM-EKD has two inf-sets special: $i_{\text {start }}$ and $i_{\text {final. }}$ inf-set $i_{\text {start }}$ is a node sourcee: $\bullet i_{\text {start }}=\varnothing$. inf-set $\mathrm{i}_{\text {final }}$ is end node: $\mathrm{i}_{\text {final }} \bullet=\varnothing$.

- $\quad$ Every node $n \in N$ is on a path from $i_{\text {início }}$ to $i_{\text {final }}$.

In the same line of Aalst (1999), the identification of inf-set start and e_inf-set final allows for a clear definition of the initial state and the final state. The BPM-EKD with multiple start infsets (i.e.inf-sets without any input arcs) or multiple final inf-sets (i.e. inf-sets without any output arcs) can easily be extended with an initialization and/or a termination part such that the first requirement is satisfied.

The second requirement demands that every inf-set is in the scope bordered by inf-set start and inf-set inicial. If the original BPM-EKD is extended with an initialization and/or a termination part such that the first requirement is satisfied, then the second requirement is quite natural. If the second requirement is not satisfied, then the BPM-EKD is:

1. composed of completely disjointed parts,

2. it has parts which are never activated or

3. parts of the event-driven process chain form a trap.

How does BPM-EKD describes the process instance, the two requirements are reasonable. The life cycle should have a clear start inf-set, an end inf-set, and all the steps should be on a path between these two events. As in Aalst (1999), in remainder of this chapter, the BPMEKD will be assumed to be regular.

One BPM-EKD describes a procedure with an initial state and a final state. The procedure should be designed in such a way that always it ends properly. Moreover, it should be possible to run any process following the proper route of BPM-EKD. 
Definition 7. A regular BPM-EKD is "sound" if, and only if:

1. For each $M$ marking reachable from the initial state (for example, the state, where the $\mathrm{i}_{\text {initial }}$ inf-set is the only inf-set that exists), there is a sequence of shots taking from the $\mathrm{M}$ marking to the final marking (for example, where the $i_{\text {final }}$ inf-set is the only inf-set that exists).

2. The only existing mark at the end of the process is in the final state $i_{\text {final }}$.

3. There are no dead processes, for example, for each process $p$ there is a shot sequence, which runs $p$.

The conformity, according to the ones of Petri nets, is the minimum requirement, so that any BPM-EKD should meet. A BPM-EKD sound is free of potential deadlocks and livelocks. If assuming fairness, then the first two requirements imply that eventually the final mark will be achieved (it is noticed that this is a result of the combination of ownership of soundness and free choice. The property free choice implies that for each transition $t 1$ e $t 2, \bullet t 1 \cap \bullet t 2 \neq \varnothing$ that implies that $\bullet t=\bullet 2$.

The complex BPM-EKD found in practice, the verification of property soundness is not simple. Fortunately, techniques and tools based on Petri nets can be used to analyze this property. The inspection of the tree coverage of Petri net that corresponds to BPM-EKD is sufficient to verify soundness. For complex BPM-EKD, the tree coverage can become very big. This phenomenon is known as the "explosion problem of state." One BPM-EKD with 80 processes can easily have more than 200,000 markings. Although the computers currently have trouble to analyze trees coverage of that size, there are many advanced techniques that explore the structure of Petri nets, in this case generated by one BPM-EKD. These techniques allow efficient procedures decision. Before presenting such procedure, primarily it is necessary to list some properties present in any Petri net generated by one BPM-EKD sound. The BPM-EKD $=(I, P, C, Q, A)$ is sound and PN $=N(B P M-E K D)$ the Petri net generated by the BPM-EKD. Consider PN be as PN with an additional $t$ transition connecting $i_{\text {final }}$ to $i_{\text {initial }}$ and let $\mathrm{M}$ to be the initial marking with a mark in $\mathrm{i}_{\text {initial }}$ (Aalst, 1999).

- $\overline{\mathrm{PN}}$ is strongly connected;

- $\overline{\mathrm{PN}}$ is susceptible of coverage;

- $(\overline{\mathrm{PN}}, \mathrm{M})$ is live and

- $\quad(\overline{\mathrm{PN}}, \mathrm{M})$ is limited.

A Petri net is strongly connected if, and only if, for each pair of nodes (places and transitions) $\mathrm{x}$ and $\mathrm{y}$, there is a path from $\mathrm{x}$ until $\mathrm{y}$ (Aalst, 1999). PN is strongly connected because all nodes are on the path from the $i_{\text {initial }}$ to the $i_{\text {final }}$ and $i_{\text {final }}$ is connected in $i_{\text {initial }}$ through additional t. PN is WF-net according to Aalst (1997). Therefore, soundness coincides with vivacity and limitation. (PN, M) is free choice, alive and limited and, according to Aalst and Hee (2002), implies that PN is susceptible of coverage and (PN, M) is secure. Building the results presented in Aalst (1997), the property of soundness can be verified in polynomial time. One BPM-EKD corresponds to a WF-net free choice. One WFnet is sound if, and only if, the extended net is alive and limited. Vivacity and limitation can be verified in time polynomial. For that reason soundness can be verified in polynomial time.

In this way, it is possible to extend tools with efficient decision procedures to verify the soundness property of one BPM-EKD. For guiding the user to look for defects and fix them in a project of one BPM-EKD it is also possible to supply additional diagnoses based on the structure of BPM-EKD/Petri nets. 


\subsection{Assessment method of Business Processes Model of EKD}

The assessment method of Business Processes Model of EKD consists of:

1. developing the organizational model EKD using the guidelines presented in Bubenko et al. (1998).

2. Developing Business Processes Model according to the formalization the BPM-EKD presented in this work. Check if the model meets the following requirements:

2.1. All processes must have input and output conditions. When a case doesn't have any input condition, it will not be clear when it may be performed. When a process doesn't have any output conditions, it does not contribute for the success of the process and can be omitted.

2.2. There must be at least one final inf-set and one initial inf-set.

2.3. The input of the process should be equal to 1 .

2.4. The output of the process should be equal to 1 .

2.5. The output of an inf-set should be equal or less than 1 . In case it is less than 1 , it is a final inf-set.

2.6. The input of inf-set should be equal or less than 1 . In case it is less than 1 , it is an initial inf-set.

2.7. The entry of the connector should be larger than or equal to 1 .

2.8. The output of the connector should be larger or equal to 1 .

2.9. Every connector should be OR or AND type.

2.10. Every connector should be Split or Join type.

2.11. Every connector should be PI or IP type.

2.12. A split-type connector should have the input equal to 1.

2.13. A split-type connector should have the output equal to 2 or larger than 2 .

2.14. A join-type connector should have the input larger than 2 or equal to 2 .

2.15. A join-type connector should have the output equal to 1 .

2.16. It is not allowed to connect process to process.

2.17. It is not allowed to connect inf-set to inf-set.

2.18. It is not allowed to use the connector linking process(es) to process(es) and inf-set (s) to inf-set (s).

2.19. It is not allowed the connection of connector (s) with connector(s).

2.20. All the inf-sets that were not generated by the process should be enabled.

3. Model mapping on Petri nets. The inf-sets are represented by places and the processes are represented by transitions. For the connectors mapping it is necessary to follow the rules presented as follows:

3.1. The set of places is formed by the union of all inf-sets with places that were included to represent the connectors.

3.2. The set of transitions is formed by the union of all Processes with transitions that were included to represent connectors.

3.3. The set of net arcs is formed by model arcs that range from I (inf-set) to P (process) and from $P$ to I and the union of the arcs included to represent connectors.

3.4. Rule 1 states that when the connector $\mathrm{c}$ belongs to $\mathrm{C}_{\mathrm{IP}}$ (path from inf-set to process) intersection of $C_{J}$ (join) intersection of $C_{A N D}$, the connector $\left(c \in C_{I P} \cap C_{J} \cap C_{A N D}\right)$ corresponds to two or more arcs on Petri nets.

3.5. Rule 2 states that when the connector $\mathrm{c}$ belongs to $\mathrm{C}_{\text {PI }}$ (path from process to inf-set) intersection of $\mathrm{C}_{\mathrm{J}}$ (join) intersection of $\mathrm{C}_{\mathrm{AND}}$, the connector $\left(\mathrm{c} \in \mathrm{C}_{\mathrm{PI}} \cap \mathrm{C}_{\mathrm{J}} \cap \mathrm{C}_{\mathrm{AND}}\right.$ ) behaves as one transition. A place for each connector input process is added. 
3.6. Rule 3 states that when the connector c belongs to $C_{I P}$ (path from inf-set to process) intersection of $C_{J}$ (join) intersection of $C_{O R}$, the connector ( $c \in C_{I P} \cap C_{J} \cap C_{O R}$ ) behaves as one place.

3.7. Rule 4 states that when the connector $\mathrm{c}$ belongs to $C_{\text {PI }}$ (path from process to inf-set)

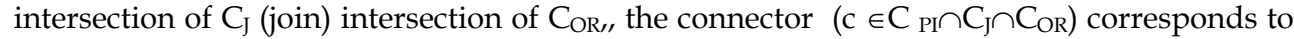
two or more arcs onto Petri nets.

3.8. Rule 5 states that when the connector $\mathrm{c}$ belongs to $\mathrm{C}_{\mathrm{IP}}$ (path from inf-set to process) intersection of $C_{S}$ (split) intersection of $C_{A N D}$, the connector $\left(c \in C_{I P} \cap C_{S} \cap C_{A N D}\right.$ ) behaves as one transition followed by a number of places equal to the number of processes.

3.9. Rule 6 states that when the connector $c$ belongs to $C_{\text {PI }}$ (path from process to inf-set) intersection of $\mathrm{C}_{\mathrm{S}}$ (Split) intersection of $\mathrm{C}_{\mathrm{AND}}$, the connector ( $\mathrm{c} \in \mathrm{C}_{\mathrm{PI}} \cap \mathrm{C}_{\mathrm{S}} \cap \mathrm{C}_{\mathrm{AND}}$ ) corresponds to a number of arcs onto Petri nets.

3.10. Rule 7 states that when the connector $\mathrm{c}$ belongs to $\mathrm{C}_{\mathrm{IP}}$ (path from inf-set to process) intersection of $\mathrm{C}_{\mathrm{S}}$ (Split) intersection of $\mathrm{C}_{\mathrm{OR}}$, the connector ( $\mathrm{c} \in \mathrm{C}_{\mathrm{IP}} \cap \mathrm{C}_{\mathrm{S}} \cap \mathrm{C}_{\mathrm{OR}}$ ) corresponds to a number of arcs onto Petri nets.

3.11. Rule 8 states that when the connector c belongs to $C_{\text {PI }}$ (path from process to inf-set) intersection of $\mathrm{C}_{\mathrm{S}}$ (Split) intersection of $\mathrm{C}_{\mathrm{OR}}$, the connector ( $\left.\mathrm{c} \in \mathrm{C}_{\mathrm{PI}} \cap \mathrm{C}_{\mathrm{S}} \cap \mathrm{C}_{\mathrm{OR}}\right)$ corresponds to one place followed by a number of transitions equal to the number of processes of the output of the connector.

4. Building the tree of reachability Through the tree of reachability is possible to verify several errors that may occur in the definition of process, even without specific knowledge of the business process. In lack of editing tool of Petri nets it is possible to verify the soundness property through the inspection of the reachability tree that corresponds to the BPM-EKD.

5. After making the mapping on Petri nets, assessing the model using an editing tool on Petri networks. In this work, Petri Net Tools have been used. The following items should be considered:

5.1. The verification of possible deadlock, as to say whenever it is not possible to run any task.

5.2. The elimination of cases that are in infinite loop (livelock).

5.3. The verification of possible tasks that can not be executed (deadtask).

5.4. The elimination of conflicts.

5.5. The verification of possible paths.

5.6. Checking the existence of marks in other places after the end condition order was completed. Once the mark appears at the end place, all other marks must have disappeared.

6. To present the report of the problems founded.

\section{The application method.}

The model that will be presented was developed on project ESPRIT ELEKTRA (Electrical Enterprise Knowledge for Transforming Applications) (ELEKTRA, 2000). The ELEKTRA project focuses mainly on application of EKD method for the management problems of changes within organizations from Greece and Sweden, generating a set of generic practices in order to apply them to other companies.

The Vattenfall case was chosen on ELEKTRA project. The project was based on a careful analysis not only of current practice and process but also of problems, of needs, of opportunities and realized future goals. 
The model is from the strategic planning process of human resources. The planning process is conducted on a strategic level. It involves formulation of policies and goals for human resources planning for Vattenfall treating the metrics on achieving the formulated goals. The model describes how the human resources planning should be integrated with the business strategic planning. Initially, based on business planning goals, it is formulated a group of goals and indicators within the domain of competence, then the goals and indicators are reported to the business area into the documents: pre-conditions for business planning / budget guidelines. Paralleled or not, the policies, guidelines and instructions are formulated from the term of private and political goals. Afterwards, communications of these policies are effectuated.

The following procedures are: running activities within the substitute (proxy) domain on competency; returning trimestrially the goals and indicators with the help of System of Group Review; presenting a summary of achieved goals and indicators; comparing achieved goals and tendencies with the proposed goals according to the private policies and business planning and review goals. On Figure 11 the modified described model to be mapped on Petri nets is presented. The inputs of process 1 have been modified for not meeting the requirement method that states that the process can only have one input. Although the method states that one initial and final inf-set should be placed, it was not possible to place a final inf-set because the end of the procedure was not clear. The connectors were added.

On Figure 12 the same model mapped on Petri nets is presented according to the method presented in this work. The connectors of the model of the process of human resources strategic planning and their corresponding rules mapping are presented on Table 1 . The elements of Petri Nets corresponding to the elements of BPM-EKD are presented on Table 2. Test result

On Figure 13 the model simulated on Petri Net Tools is presented. A tree of reachability presented on figure 14 shows that the Pr6 transition will be shot unless there is a mark at IS8 place. As there is not such a mark before the shot of Pr7 transition there will be a deadlock. Moreover, there is not a clear end condition. The model is not sound.

\section{Final considerations}

It was emphasized that the main problem of Organizational modeling approaches, including the EKD, is the absence of techniques for objective analysis. The techniques of analysis with mathematical rigor are not usual for business area professionals. It was confirmed that the Petri nets solve this problem, once they have graphic representation, are easy to learn, function as language of communication among experts from several areas, allow the description of static and dynamic aspects of the system to be represented, and still have the mathematical formalism that allows the use of important methods of analysis.

The business processes, regularly, have a simple structure before being introduced in systems of advanced information, such as system of workflow. This simplicity is due mainly to the fact that a document can only be in one place at the same moment. The document serves as a set of marks that ensure the performance sequential tasks. Currently, after several years of development of systems in a sequential way, it is possible to model processes in a completely different order, once the information and data can be shared. Several people can work at the same time in the same case. For this reason it is not always possible to perform the tasks sequentially. Through the utilization of parallel business 
processes it is possible to achieve enormous reductions on the performance time. The business environment is opportune to perform the tasks in parallel according to the necessity. However, the utilization of sequential, parallel, selective and iterative routes in the same process makes the assessment of the defined processes difficult.

In this way, the research showed that the Business Processes Model should be developed with great care, because, in addition to problems resulting from errors in the project being difficult to detect, the costs of correcting the errors are high. The ambiguities and conflicts should be eliminated of the models.

It was possible to confirm that ambiguities and confusion cannot be prevented on informal Business Processes model. To solve this problem, a Business Processes Model with a formal semantic was developed. To develop this semantic a connector set for Business Processes Model of EKD was created. The connectors set represented by $C$ and composed by $C_{A N D}, C_{O R}$, $\mathrm{C}_{\mathrm{J}}, \mathrm{C}_{\mathrm{S}}, \mathrm{C}_{\mathrm{IP}}$ and $\mathrm{C}_{\mathrm{PI}}$. The connectors $\mathrm{C}_{\mathrm{OR}}$ and $\mathrm{C}_{\mathrm{AND}}$ are important to identify (exclusive) choice and parallelism for the cases of parallelism and choice won't be exactly modeled in the same way, avoiding ambiguities and comprehension difficulties. The connectors $C_{J}$ and $C_{S}$ define connectors join and split type. The connectors $\mathrm{C}_{\mathrm{IP}}$ and $\mathrm{C}_{\mathrm{PI}}$ show that a connector $\mathrm{c}$ is a path from an inf-set to a process or a path from a process to an inf-set.

The initial and final states were included to enable that the formalization be effectively accomplished. These states are not specified in the Business Processes Model of original EKD.

In this work a procedure of formal mapping of Business Processes Model on Petri nets was developed. The procedure of mapping was developed based on Petri nets place transition. Through a business process model mapped on Petri nets in accordance with this procedure, it was possible to verify some requirements that ensure if the process was correctly modeled and other requirements that allow the process analysis.

Thus, the Assessment Method of Business Processes Model of EKD was created from the procedure of formal mapping of the Business Processes Model on Petri nets. The method consists on a sequence of steps that ranges from the development of organizational model to the construction of reachability tree and simulation of model in tool.

The application of the method allows verifying the presence of deadlock, in which the process can never be accomplished. Moreover, there is no clear end condition, so the model is not sound.

Based on these problems, it can be stated that the care on the modeling process is fundamental in order that the model represents faithfully the way the process is performed and that these problems are minimized when the model is developed in accordance with the method developed in this work.

The great convenience, as previously stated, in using Petri nets in business processes model is the possibility of a thorough tracking and non-ambiguous on each step of the operation.

Moreover, this work shows that Petri nets enable a formal mathematical representation and provide mechanisms of analysis that make possible the verification of the model correction and the checking of their properties.

The fact that some constructions are not allowed can be considered a disadvantage of the BPM-EKD formalization. But, during the process of modeling these constructions should be carefully analyzed, being important the discernment of the team or person who is modeling in order that the model be developed in accordance with the created settings in this work. It is important to emphasize that the application of assessment method in many Business Processes Models can be impractical without a tool computer that supports all steps of the method. 


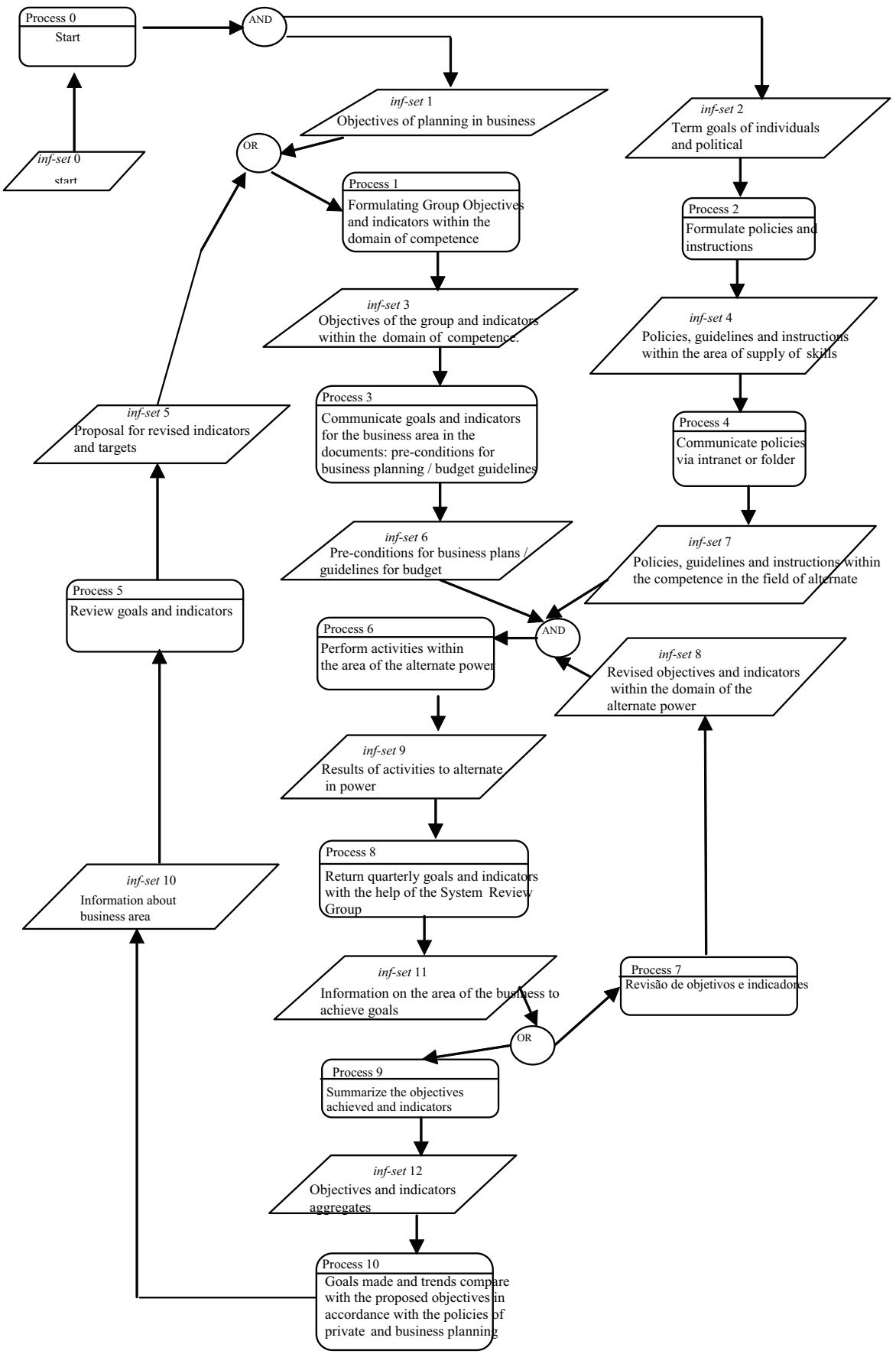

Fig. 10. Model Procedure for strategic planning of human resources changed. 


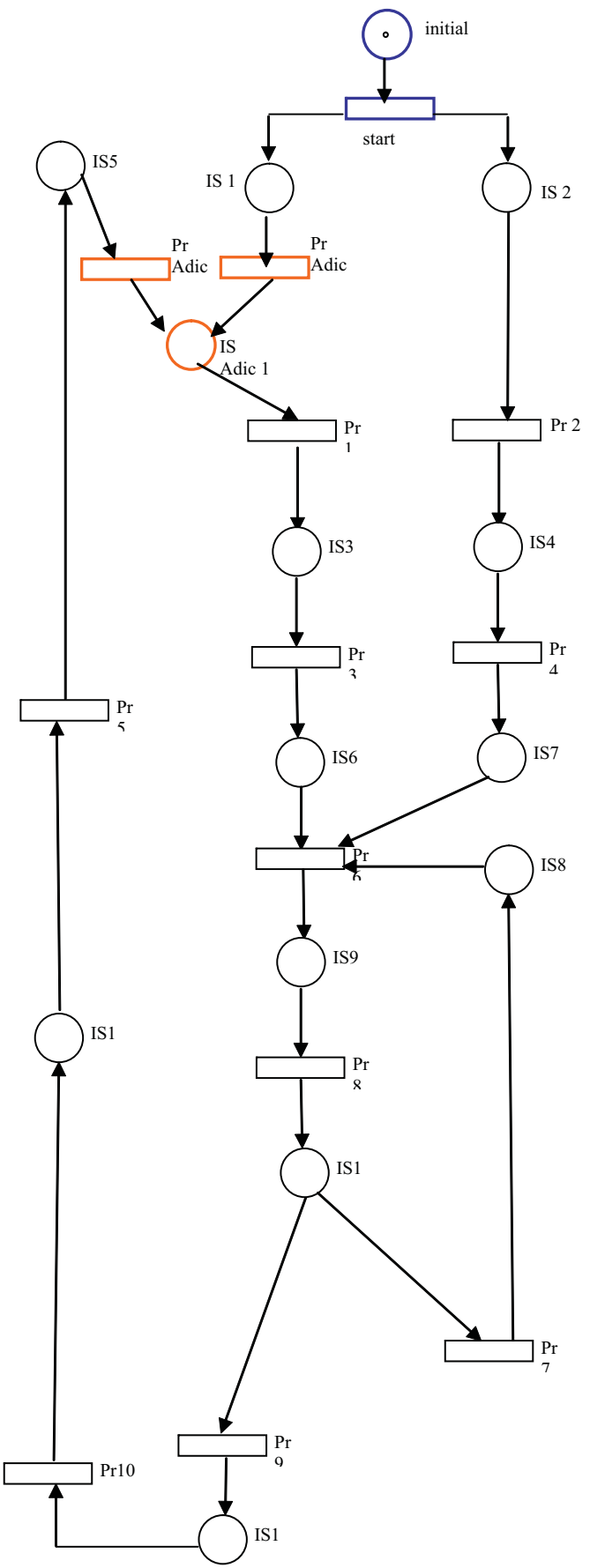

Fig. 11. Strategic planning model mapped to the Petri nets. 


\begin{tabular}{|l|l|}
\hline Conector & Rule corresponding \\
\hline$C_{\mathrm{PI}} \mathrm{C}_{\mathrm{S}} \mathrm{C}_{\mathrm{AND}}$ & Rule 6 \\
\hline $\mathrm{C}_{\mathrm{IP}} \mathrm{C}_{\mathrm{J}} \mathrm{C}_{\mathrm{OR}}$ & Rule 3 \\
\hline $\mathrm{C}_{\mathrm{IP}} \mathrm{C}_{\mathrm{J}} \mathrm{C}_{\mathrm{AND}}$ & Rule 1 \\
\hline $\mathrm{C}_{\mathrm{IP}} \mathrm{C}_{\mathrm{S}} \mathrm{C}_{\mathrm{OR}}$ & Rule 7 \\
\hline
\end{tabular}

Table 1. Connectors used in the model of strategic human resource planning and mapping corresponding Rule.

\begin{tabular}{|c|c|c|}
\hline PN & BPM-EKD & \\
\hline Place & inf-set & Description \\
\hline Is1 & 1 & Objectives of planning in business \\
\hline Is2 & 2 & Term goals of individuals and political \\
\hline Is3 & 3 & $\begin{array}{l}\text { Objectives of the group and indicators within the domain } \\
\text { of competence. }\end{array}$ \\
\hline Is4 & 4 & $\begin{array}{l}\text { Policies, guidelines and instructions within the area of } \\
\text { supply of skills }\end{array}$ \\
\hline Is5 & 5 & Proposal for revised indicators and targets \\
\hline Is6 & 6 & Pre-conditions for business plans / guidelines for budget \\
\hline Is7 & 7 & $\begin{array}{l}\text { Policies, guidelines and instructions within the } \\
\text { competence in the field of alternate }\end{array}$ \\
\hline Is8 & 8 & $\begin{array}{l}\text { Revised objectives and indicators within the domain of the } \\
\text { alternate power }\end{array}$ \\
\hline Is9 & 9 & Results of activities to alternate in power \\
\hline Is10 & 10 & Information on area business \\
\hline Is11 & 11 & Information on the area of the business to achieve goals \\
\hline Is12 & 12 & Objectives and indicators aggregates \\
\hline Tr & Pr & Description \\
\hline Pr1 & 1 & $\begin{array}{l}\text { Formulating Group Objectives and indicators within the } \\
\text { domain of competence }\end{array}$ \\
\hline Pr2 & 2 & Formulate policies \\
\hline Pr3 & 3 & $\begin{array}{l}\text { Communicate goals and indicators for the business area in } \\
\text { the documents: pre-conditions for business planning / } \\
\text { budget guidelines }\end{array}$ \\
\hline Pr4 & 4 & Communicate policies via intranet or folder \\
\hline Pr5 & 5 & Review goals and indicators \\
\hline Pr6 & 6 & Perform activities within the area of the alternate power \\
\hline Pr7 & 7 & Review of objectives and indicators \\
\hline Pr8 & 8 & $\begin{array}{l}\text { Return quarterly goals and indicators with the help of the } \\
\text { System Review Group }\end{array}$ \\
\hline Pr9 & 9 & Overview of goals achieved and indicators \\
\hline Pr10 & 10 & $\begin{array}{l}\text { Goals made and trends compare with the proposed } \\
\text { objectives in accordance with the policies of private and } \\
\text { business planning }\end{array}$ \\
\hline
\end{tabular}

Table 2. Elements of Petri networks corresponding to the elements of BPM-EKD of Strategic Planning 


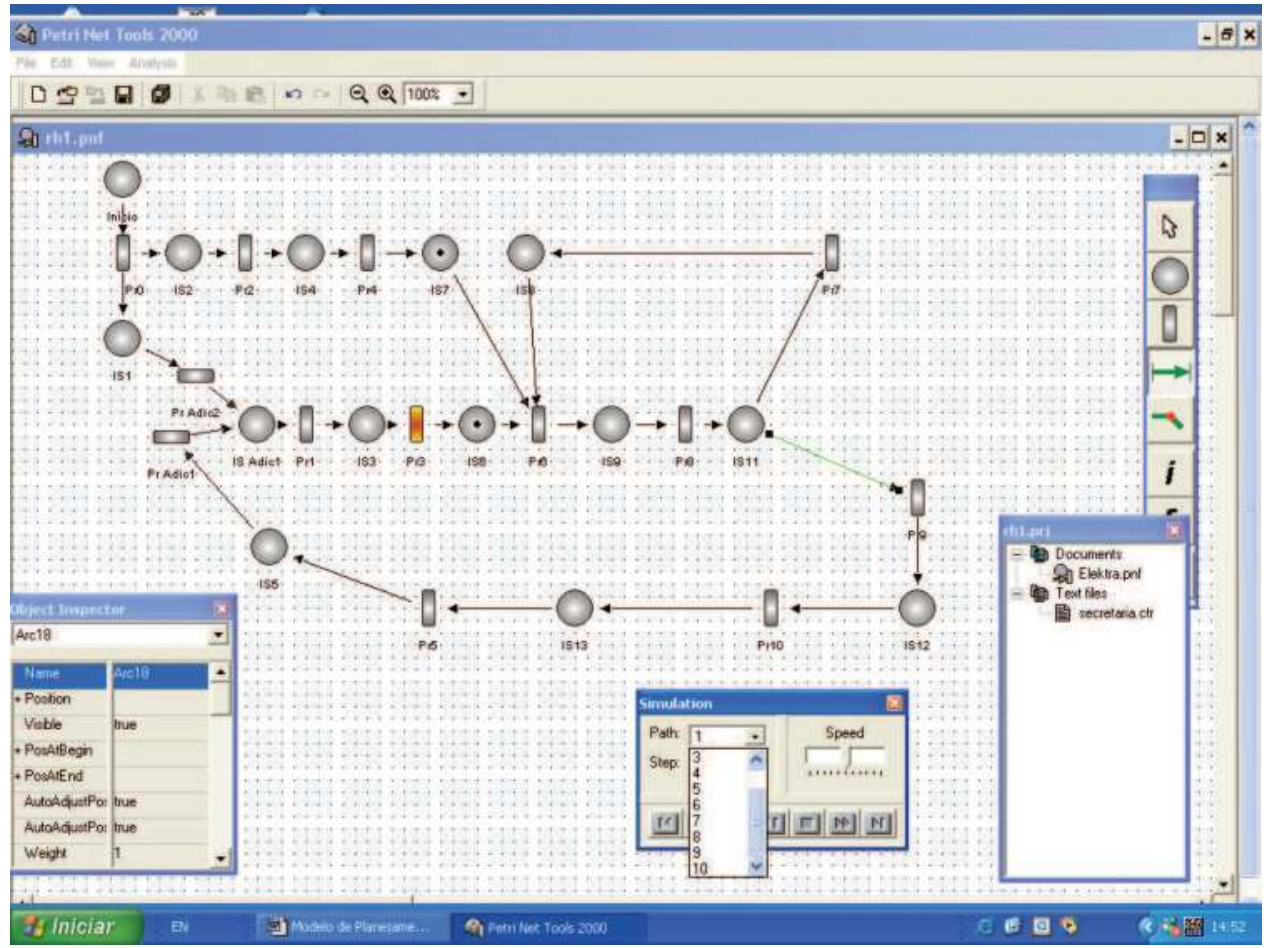

Fig. 12. Simulation Model of the Strategic Planning Tool in Petri Net Tools.

\section{Acknowledgments}

The authors of this paper are especially grateful to Prof. Dr. Adenilso da Silva Simão and the CAPES.

\section{References}

AALST, W.M.P.V.D. Formalization and verification of event-driven process chains. Information and Software Technology, London, v.41, n.10, p.639-650, July, 1999.

Verification of workflow nets. In: AZEMA, P.; BALBO, G. (Eds.). Application and theory of petri nets. Berlin: Springer-Verlag, 1997. (Lectures Notes in Computer Science).

AALST, W. M. P. V. D; HOFSTEDE, A. H. M. T. Verification of workflow task structures a petri-net-based approach. Information Systems, Oxford, v.25, n.1, p.43-69, 2000.

AALST, W.V.D.; HEE, V.K. Workflow management: models, methods and systems. Cambridge: MIT Press, 2002.

BUBENKO JR., J. A.; STIRNA, J.; BRASH, D. EKD user guide, Dpt of computer and systems sciences. Stockholm: Royal Institute of Technology, 1998.

CHRZASTOWSKI-WACHTEL, P. et al. A top-down petri net-based approach for dynamic workflow modeling. In: INTERNATIONAL CONFERENCE BPM, 2003, Eindhoven. Proceeding... Berlin: Springer, 2003. p. 336-353. 


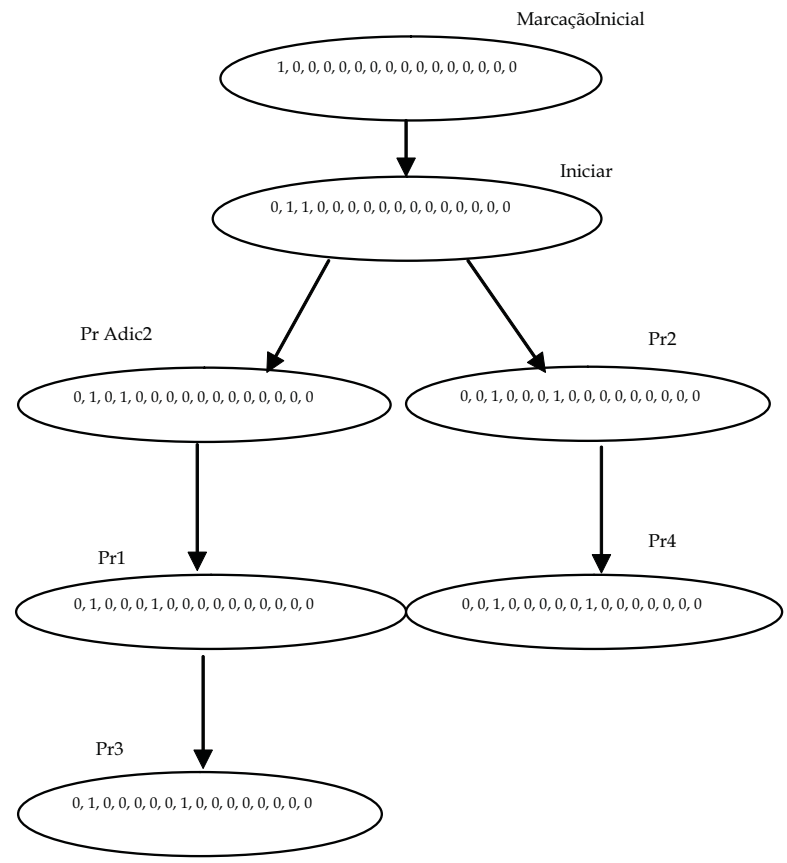

Fig. 13. Tree under the Model of Strategic Planning of Petri nets in mapped.

DALLAVALLE, S. I.; CAZARINI, E. W. Modelagem organizacional desenvolvimento do conhecimento organizacional, facilitador de desenvolvimento de sistemas de informação. In: Encontro Nacional de Engenharia de Produção, 11., 2001, Salvador. Anais... Salvador, 2001. CD-ROM.

DEHNERT, J. Four steps towards sound business process models. In: EHRIG., H. et al. (Eds.). Petri net technology for communication-based systems- advances in petri nets. Berlin: Springer, 2003. p. 66-82. (Lecture Notes in Computer Science, 2472).

DONGEN, V. B. F. et al. Verification of the SAP reference models using EPC reduction, state-space analysis, and invariants. Computers in Industry, Amsterdam, v. 58, n. 6, p. 578-601, 2007.

ELEKTRA. ELECTRICAL enterprise knowledge for transforming applications. The ELEKTRA project programme. Disponível em:

<www.singular .gr/elektra.ekd.htm>. Acesso em: 27 Nov. 2000.

GRIGOROVA, K. Process modelling using petri nets. In: INTERNATIONAL CONFERENCE ON COMPUTER SYSTEMS AND TECHNOLOGIES: E-Learning, 4., 2003, Rousse. Disponível em: <http:/ /doi.acm.org/10.1145/973620.973636>. Acesso em: 14 June. 2004.

GUAN, F. et al. Grid-flow: a grid-enabled scientific workflow system with a Petri-net-based interface. Concurrency and Computation: Practice and Experience, Chichester, v.18, n.10, p. 1115 - 1140, 2006.

INAMASU, R. Y. Modelo de FMS: uma plataforma para simulação e planejamento. 134p. Tese de Doutorado - Escola de Engenharia de São Carlos, Universidade de São Paulo, São Carlos, 1995

JACOBSON, I.; BOOCH, G.; RUMBAUGH, J. The unified software development process. Reading: Addison-Wesley, 1999. 
JENSEN, K. A Brief Introduction to Coloured Petri Nets. In: Brinksma, E.: Lecture Notes in Computer Science, Vol. 1217: Tools and Algorithms for the Construction and Analysis of Systems. Proceedings of the TACAS'97 Workshop, Enschede, The Netherlands 1997, p. 201-208. Springer-Verlag, 1997.

JONKERS, $\mathrm{H}$. et al. Towards a language for coherent enterprise architecture descriptions. In: IEEE INTERNATIONAL ENTERPRISE DISTRIBUTED OBJECT COMPUTING CONFERENCE, 7., 2003, Brisbane. Proceedings... Los Alamintos: IEEE Computer Society, 2003.

JUNGINGER, S. et al. Building complex workflow applications: how to overcome the limitations for the waterfall model. In: FISCHER, L. (Ed.). Workflow management coalition: the workflow handbook 2001. Disponível em:<http://www.boceu.com/english/papers/Complex_Workflow_Appl.pdf>. Acesso em: 16 apr. 2001.

KOUBARAKIS, M.; PLEXOUSAKIS, D. A formal framework for business process modelling and design. Information Systems, Oxford, v.27, n.5, p. 299-319, jul. 2002

KRUCHTEN, P. The rational unified process. 2nd ed. Harlow: Addison-Wesley, 2000.

LENZ, K.; MEVIUS, M.; OBERWEIS, A. Process-Oriented business performance management with petri nets. In: CHEUNG, W.; HSU, J. (Eds.). Proceeding of the 2nd IEEE conference on e-technology, e-commerce and e-service. Hong-Kong, 2005. p. 89-92.

MEVIUS, M.; OBERWEIS, A. A Petri-Net based approach to performance management of collaborative business processes. In: International Workshop on Database and Expert Systems Applications (DEXA'05), 16., 2005. Proceeding... Karlsruhe: University of Karlsruhepp, 2005. 987-991.

MOLD, D.; VALK, R. Object oriented petri net in business process modeling. In: AALST, V. D. W.; DESEL, J.; OBERWEIS, A. Business process management: models, techniques, and empirical studies. Berlin: Springer, 2000. p. 254-273. (Lectures Notes in Computer Sciences, 1806).

MURATA, T. (1989). Petri net: properties, analysis and applications. Proceedings of the IEEE, v.77, n.4, p.541-579.

NURCAN, A.; ROLLAND, C. A multi-method for defining the organizational change. Journal of Information and Software Technology, London, v. 45, n. 2, p.61-82, feb. 2003

NURCAN, S. Analysis and design of co-operative work process a framework. Information and Software Technology, London, v. 40, n. 3, p.143-156, jun. 1998.

NURCAN, S.; BARRIOS, J. Enterprise knowledge and information system modelling in na evolving enviroment. In: INTERNATIONAL WORKSHOP ON ENGINEERING METHODS TO SUPORT INFORMATION SYSTEMS EVOLUTION IN CONJUNCTION WITH, 2003, Geneva. Proceedings... Geneva: Switzerland, 2003 disponível em <http://cui.unige.ch/db-research/EMSISE03/Rp07.pdf>. acesso em 11 apr. 2008.

OU-YANG, C.; LIN Y. D. BPMN-based business process model feasibility analysis: a petri net approach. International Journal of Production Research, London, v. 45, n. 12, 2007.

PÁDUA, S. I. D. Investigação do processo de desenvolvimento de software a partir da modelagem organizacional, enfatizando regras do negócio. 145 p. Dissertação (Mestrado) - Escola de Engenharia de São Carlos, Universidade de São Paulo, São Carlos, 2001.

PÁDUA, S. I. D. Método de avaliação do modelo de processos de negócios. 252 p. Tese (Doutorado) - Escola de Engenharia de São Carlos, Universidade de São Paulo, São Carlos, 2004.

PÁDUA, S. I. D.; CAZARINI, E.W..; INAMASU, R. Y. Modelagem organizacional: captura dos requisitos organizacionais no desenvolvimento de sistemas de informação. Revista Gestão e Produção, São Carlos, v.11, n.2, p.1-20, maio-ago. 2004a. 
PÁDUA, S. I. D.; SILVA, A. R. Y.; INAMASU, R. Y.; PORTO, A. J. V. Aplicações e potencial das redes de Petri na Engenharia de Produção. In: Simpósio de Engenharia de Produção, 10., 2003. Disponível em: http://www.bauru.unesp.br/acontece/simpep.html. Acesso em: 30 nov. 2003.

PÁDUA, S. I. D.; SILVA, A. R. Y.; INAMASU, R. Y.; PORTO, A. J. V. O potencial das redes de Petri em modelagem e análise de processos de negócios. Revista Gestão e Produção, São Carlos, v.11, n.1, p.1-11, abr. 2004b.

PÁDUA, S. I. D.; SILVA, A. R. Y.; INAMASU, R. Y.; PORTO, A. J. V. Redes de petri aplicadas aos sistemas de gerenciamento de Workflow. In: Encontro Nacional de Engenharia de Produção, 12., 2002, Curitiba. Anais... Curitiba, 2002. CD-ROM.

PERSSON, A. The utility of participative enterprise modelling in IS development: challenges and research issues. In: INTERNATIONAL WORKSHOP ON THE REQUIREMENTS ENGINEERING PROCESS, 2., 2000, Greenwich. Proceedings... Berlin: Springer, 2000. p. 978-982.

PETERSON, J.L. Petri nets: theory and modelling of systems. Englewood Cliffs: Prentice-Hall, 1981.

RINDERLE, S.; REICHERT, M.; DADAM, P. Evaluation of correctness criteria for dynamic workflow changes. In: INTERNATIONAL CONFERENCE BPM 2003, 2003, Eindhoven. Proceedings... Berlin: Springer, 2003. p.41-57. (Lecture Notes in Computer Science, 2678).

ROLLAND, C.; NURCAN, S.; GROSZ, G. A Decision making pattern for guiding the enterprise knowledge development process. Journal of Information and Software Technology, London, v.42, n. 5, p.313-331, apr. 2000.

SALIMIFARD, S.; WRIGHT M. Petri net based modelling of workflow systems: an overview. European Journal of Operational Research, Amsterdam, v.134, n.3, p.664676, nov.2001.

SOARES, J.B. Editor de modelos de sistemas de eventos discretos, baseado em redes de Petri interpretadas. 2001. Dissertação (Mestrado) - Escola de Engenharia de São Carlos, Universidade de São Paulo, São Carlos, 2001.

VERBBEK H. M. W.; AALST, W. M. P.; HOFSTEDE, A. H. M. Verifying workflows with cancellation regions and OR-joins: an approach based on relaxed soundness and invariants. The Computer Journal Advance, Oxford, v. 50, n. 3, p. 294-314, 2007.

VERBEEK, H. M. W.; BASTEN, T.; AALST, W. M. P. Diagnosing workflow using woflan. Eindhoven: Eindhoven University of Technology, 2002. (BETA Working Paper Series, WP 48).

VOORHOEVE, M. Compositional modeling and verification of workflow process. In: AALST,V. D. W.; DESEL, J.; OBERWEIS, A. Business process management: models, techniques, and empirical studies. Berlin: Springer, 2000. p. 184-200. (Lectures Notes in Computer Sciences, 1806).

WORKFLOW management coliation: reference model. Hampshire, 1996. (Document Number WFMC-TC00-1003).

ZHANG, L.; SHUZHEN, Y. Research on workflow patterns based on Petri nets. In: IEEE CONFERENCE ON CYBERNETICS \& INTELLIGENT SYSTEMS (CIS) ROBOTICS, AUTOMATION AND MECHATRONICS (RAM), 2006, Bangkok. Proceeding... Bangkok: IEEE Computer Society, 2006. p. 1-6.

ZISMAN, M. D. Representation, specification and automation of office procedures. Thesis (PhD) - University of Pennsylvania, Wharton School of Business, Pennsylvania, 1977. 


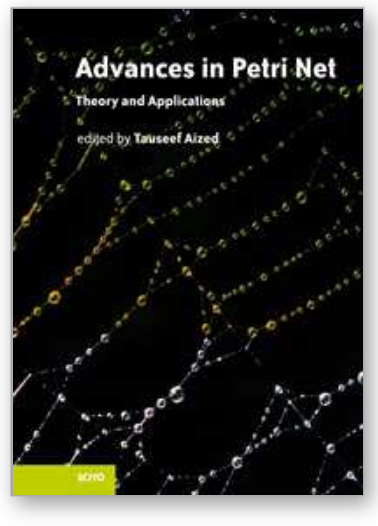

\author{
Advances in Petri Net Theory and Applications \\ Edited by Tauseef Aized
}

ISBN 978-953-307-108-4

Hard cover, 220 pages

Publisher Sciyo

Published online 27, September, 2010

Published in print edition September, 2010

The world is full of events which cause, end or affect other events. The study of these events, from a system point of view, is very important. Such systems are called discrete event dynamic systems and are of a subject of immense interest in a variety of disciplines, which range from telecommunication systems and transport systems to manufacturing systems and beyond. There has always been an intense need to formulate methods for modelling and analysis of discrete event dynamic systems. Petri net is a method which is based on a wellfounded mathematical theory and has a wide application. This book is a collection of recent advances in theoretical and practical applications of the Petri net method and can be useful for both academia and industry related practitioners.

\title{
How to reference
}

In order to correctly reference this scholarly work, feel free to copy and paste the following:

Silvia Inês Dallavalle De Padua and Ricardo Inamasu (2010). Assessment Method of Business Process Model of EKD, Advances in Petri Net Theory and Applications, Tauseef Aized (Ed.), ISBN: 978-953-307-108-4, InTech, Available from: http://www.intechopen.com/books/advances-in-petri-net-theory-andapplications/assessment-method-of-business-process-model-of-ekd

\section{INTECH}

open science | open minds

\section{InTech Europe}

University Campus STeP Ri

Slavka Krautzeka 83/A

51000 Rijeka, Croatia

Phone: +385 (51) 770447

Fax: +385 (51) 686166

www.intechopen.com

\section{InTech China}

Unit 405, Office Block, Hotel Equatorial Shanghai

No.65, Yan An Road (West), Shanghai, 200040, China 中国上海市延安西路65号上海国际贵都大饭店办公楼405单元

Phone: $+86-21-62489820$

Fax: +86-21-62489821 
(C) 2010 The Author(s). Licensee IntechOpen. This chapter is distributed under the terms of the Creative Commons Attribution-NonCommercialShareAlike-3.0 License, which permits use, distribution and reproduction for non-commercial purposes, provided the original is properly cited and derivative works building on this content are distributed under the same license. 